\title{
RESSENYES
}

PéreZ-Olivares, Alejandro (2018)

Victoria y control en el Madrid ocupado. Los del Europa (1939-1946)

Madrid: Traficantes de Sueños, 211 p. (Publicat sota llicència Creative Commons 3.0)

ISBN 978-84-948068-6-5

El 20 d'abril de 1939, quan amb prou feines havien passat tres setmanes de l'ocupació de Madrid per l'exèrcit franquista, un comandant d'artilleria del servei d'aviació es va presentar a la seu del Servicio de Información y Policía Militar del carrer Almagro, a Madrid, i va denunciar, amb noms i cognoms, els sospitosos d'haver col-laborat en l'assassinat del seu pare i el seu cunyat, esdevingut tres anys abans, en ple setge de Madrid per les tropes de Franco. Aquest és el fil narratiu de Victoria y control en el Madrid ocupado. Los del Europa (1939-1946), uns fets que, amb innumerables variacions, es van reproduir milers de vegades durant aquestes dates arreu de la geografia de l'Espanya franquista.

El llibre que ha escrit Alejandro Pérez-Olivares, però, no és pas un llibre d'història local. Tampoc és (només) una microhistòria de la cadena d'esdeveniments posada en marxa per una denúncia en la postguerra franquista. A partir d'un cas d'estudi inquietant, Pérez-Olivares basteix un diàleg entre el present $\mathrm{i}$ el passat, una reflexió sobre la violència i les polítiques de control polític i soci- al —avui i en la dècada de 1940- El resultat és una història de control, entès «com una forma de violència projectada sobre les conductes i sobre els espais» (p. 34), una història que il.lustra com la repressió i la por es van obrir pas fins al moll de l'os de les ciutats «alliberades» per les tropes de Franco. Una història, finalment, que mostra com la victòria franquista es va projectar sobre l'espai urbà en un barri obrer — de Tetuán de las Victorias a Cuatro Caminos- on els sospitosos residien i havien teixit les seves afinitats polítiques i sindicals.

Alejandro Pérez-Olivares, actualment professor associat a Sciences Po Lyon, és un historiador format a la Facultad de Geografía e Historia de la Universidad Complutense de Madrid (UCM). És membre del grup de recerca Espacio, Sociedad y Cultura en la Edad Contemporánea, dirigit per Luis Enrique Otero Carvajal i Gutmaro Gómez Bravo, que en els darrers anys ha contribuït a la recerca en història urbana a l'Estat amb abundants publicacions. Una part significativa de les investigacions plantejades per aquest grup durant els últims anys 
s'ha dirigit a la renovació de l'anàlisi de la Guerra Civil Espanyola a la ciutat de Madrid. Pérez-Olivares hi ha participat activament, per exemple, coordinant amb Daniel Oviedo el llibre Madrid, una ciudad en guerra, 1936-1948 (Madrid: Los Libros de la Catarata, 2016). La seva tesi doctoral, defensada l'any 2017, està dedicada a l'estudi de l'ocupació de Madrid per l'exèrcit franquista i a les polítiques de control i ordre públic desplegades a la ciutat ${ }^{1}$. Una de les fonts arxivístiques revisades sistemàticament per l'autor van ser els sumaris judicials oberts durant els anys de la postguerra. Va ser durant aquesta part de la recerca quan l'autor va ensopegar amb el sumari número 13.769, que investigava les activitats de disset homes i una dona vinculats al Cinema Europa, al barri de Tetuán, convertit en caserna i centre de detenció durant la Guerra Civil.

El llibre es divideix en un prefaci, una introducció, tres parts i un epíleg, seguit d'una secció dedicada a discutir les fonts i referències utilitzades. Aquest darrer apartat no és una simple bibliografia o llista de notes, sinó que conforma una part íntegra de l'aposta narrativa de l'autor i mereix ser comentada en primer lloc. Crida l'atenció que, malgrat ser una recerca exhaustiva, Victoria y control en el Madrid ocupado no tingui notes al peu. Aquesta elecció conscient permet al seu autor centrar-se en la narració dels fets que li interessen, relligats amb la història de la seva pròpia investigació. Els lectors, doncs, l'acompanyen, a través de les pàgines del sumari número $13.769 \mathrm{i}$ pels carrers del barri de Tetuán, des del centre de detenció del Cinema Europa fins a les superpoblades presons de la postguerra a Madrid. L'estructura narrativa és un intent reeixit de facilitar la lectura del text $\mathrm{i}$ alhora discutir les fonts arxivístiques $\mathrm{i}$ les referències emprades en una secció que té el mateix pes que les anteriors, en lloc de recloure -utilitzant l'expressió de Marc Bloch-aquestes reflexions en el «subsol» de cadascuna de les pàgines del llibre. Aquells lectors interessats a documentar totes les afirmacions de l'autor quedaran satisfets amb la secció final del llibre, de la qual probablement gaudiran tant o més que de les anteriors.

En el prefaci, l'autor fa explícites les inquietuds darrere la seva recerca, connectades amb una concepció de la història entesa com una "disciplina construïda i reconstruïda constantment des del present en què s'escriu» (p. 37). En aquest present, l'aprovació de la llei mordassa o l'impacte del cas Ciutat Morta són els autèntics punts de partida del llibre, exemples esmentats per l'autor a l'hora d'expressar la seva preocupació per l'extensió de les polítiques de control a l'espai públic. Amb un enfocament influït per la microhistòria, la recerca de Pérez-Olivares explora un cas que illustra les arrels violentes de la dictadura franquista, amb l'esperança que el llibre pugui servir per reflexionar sobre l'actual extensió del control social com a pràctica repressiva i sobre la seva acceptació acrítica per bona part de la població.

La introducció del llibre presenta la denúncia que va posar en marxa la investigació policial, i contextualitza el cas del Cinema Europa en el convuls Madrid de la Guerra Civil. L'ocupació de la ciutat a final de març de 1939, el subseqüent ban de guerra i l'edicte de l'auditoria de guerra de l'exèrcit d'ocupació són el rerefons polític i legal dels milers de denúncies registrades a la capital durant els primers mesos de l'ocupació. A continuació, la primera part del llibre se centra en els interrogatoris dels detinguts a la comissaria del carrer Almagro. L'autor és conscient dels reptes que una font documental com l'acta d'un interrogatori policial franquista suposa

1. Alejandro Pérez-Olivares (2017). La victoria bajo control. Ocupación, orden público y orden social del Madrid franquista (1936-1948). Universidad Complutense de Madrid. 
per l'historiador que l'interpreta, i llegeix en els signes de puntuació i les estructures de les declaracions dels interrogats, registrades pels funcionaris, el traç de la violència física i la tortura. Amb la finalitat de superar les limitacions de la font documental en què es basa, Pérez-Olivares opta per recrear els diàlegs entre interrogadors $\mathrm{i}$ interrogats fent explícita la presència de la violència. Aquest recurs no serà del gust de tothom, però cal destacar que és una opció conscient i valenta, orientada a visualitzar els silencis d'una font documental problemàtica.

A la segona i a la tercera part del llibre, l'autor trasllada el focus de les sales d'interrogatori als carrers propers al Cinema Europa i a les presons plenes a vessar del primer franquisme, a les quals van a parar disset homes i una dona detinguts com a resultat de la denúncia. Pérez-Olivares mostra de forma efectiva la distribució espacial de la multitud d'interrogatoris, informes i avals que es produeixen durant les diferents etapes del consell de guerra. Mitjançant el mapa que encapçala el llibre i d'altres que estan inclosos a les seves pàgines, l'autor traça la investigació de les autoritats franquistes — policia, Falange, Guàrdia Civilsobre l'espai urbà de la capital. I el dibuix resultant delimita ben clarament l'espai de sociabilitat dels processats: l'escala de barri, on el control social pren cos en les declaracions de coneguts, veïns, caps de casa i particularment els porters, figures a mig camí entre l'espai públic i el privat.

El periple judicial i penal dels detinguts es desvela entre la tercera part i l'epíleg del llibre. Quan els processats van anar abandonant la presó a partir de 1945 , la majoria ho va fer amb la llibertat condicional, amb l'obligació de presentar-se a les Juntas Locales de Libertad Vigilada el primer diumenge de cada mes. Sortien d'una presó, doncs, per entrar a una altra. Disciplinats per anys d'incertesa i violència darrere els barrots, amb la pena de mort planant sobre seu, els condemnats van abandonar la vida penitenciària convertits en ciutadans diferents, i van retornar a uns barris i unes llars on les polítiques de control de la dictadura franquista estenien les seves arrels.

Hi ha milers d'històries com la que Pérez-Olivares explica a Victoria y control en el Madrid ocupado. Exhumar-les i analitzar-les de forma crítica és necessari per entendre les arrels violentes d'una de les dictadures més longeves del segle XX, així com per interpretar les actituds polítiques $\mathrm{i}$ les pors de les persones que van sobreviure al seu pas per les sales d'interrogatori, els tribunals i les presons franquistes. En la comprensió d'aquesta violència, la dimensió espacial de les polítiques de control social és fonamental. Però, com bé recorda l'autor, aquestes polítiques no són cosa del passat, i per tant la història, més enllà de ser una reconstrucció més o menys encertada d'aquells temps, pot ser també una veu d'alarma, tal com va escriure Walter Benjamin. La innovadora proposta narrativa i interpretativa de Pérez-Olivares resulta reeixida en ambdós sentits. És d'agrair, finalment, que Traficantes de Sueños publiqui i distribueixi propostes d'aquesta qualitat sota la llicència Creative Commons 3.0 i les posi a l'abast del gran públic a les llibreries i també mitjançant l'opció de descarregarles lliurement a la seva web. Una aposta per la cultura lliure i de qualitat que no hauria de passar desapercebuda.

\section{Santiago Gorostiza}

Centre d'Histoire de Sciences Po santiago.gorostiza@sciencespo.fr https://doi.org/10.5565/rev/dag.626 